Estudios Constitucionales, Año 13, № 2, 2015, pp. 237-272

ISSN 07180195

Centro de Estudios Constitucionales de Chile Universidad de Talca

"El procedimiento de reforma, la participación popular

y las reformas de la Constitución en Cuba (1959-2002)"

Teodoro Yan Guzmán Hernández

\title{
EL PROCEDIMIENTO DE REFORMA, LA PARTICIPACIÓN POPULAR Y LAS REFORMAS DE LA CONSTITUCIÓN EN CUBA (1959-2002)*
}

\author{
THE PROCEDURING, THE POPULAR PARTICIPATION \\ And the Amendments to the Constitution in Cuba (1959-2002)
}

\author{
Teodoro Yan GuZmán Hernández** \\ Facultad de Derecho de la Universidad de La Habana \\ yan@lex.uh.cu / tyguzman@gmail.com
}

RESUMEN: El siguiente trabajo se adelanta a una nueva reforma de la Constitución cubana y analiza, desde una perspectiva histórico-constitucional, las modificaciones que ha sufrido la misma, en el periodo de 1959 al 2002. Los centros de análisis son el procedimiento de reforma, por su relación lógica con el principio de supremacía constitucional, y la participación popular, por su tributo a la legitimidad democrática del cambio. En sus conclusiones deja abierto el debate acerca de los nuevos retos que tendría una nueva reforma constitucional, que apele a la participación popular y sacrifique una vez más la legalidad del mecanismo.

ABSTRACT: This paper precedes a new reform of Cuban Constitution and analyses, from a historical and constitutional perspective, its changes which occurred during the period from 1952 to 2002. The core of the analysis is both the clause of the reform, for its logical relation with the principle of the constitutional supremacy and the popular participation due to its contribution to the democratic legitimacy of change. In its final part, it leaves the debate open on the new challenges of a new constitutional reform which claims for a popular participation and sacrifices again the legality of the mechanism.

PALABRAS CLAVE: Constitución, reforma constitucional, procedimiento de reforma, participación popular y legitimidad.

KEYWORDS: Constitution, constitutional reform, procedure of reform, popular participation and legitimacy.

* Trabajo recibido el 10 de octubre de 2014 y aprobado el 27 de mayo de 2015.

** Teorodo Yan Guzmán Hernández, profesor de la Facultad de Derecho de la Universidad de La Habana desde el 2002. Doctor en Ciencias Jurídicas por la misma universidad en 2007. Imparte las asignaturas Teoría del Estado, Derecho Constitucional y Teoría del Derecho. Ha publicado varios trabajos en revistas y artículos periodísticos sobre la participación política y sus formas, así como sobre la democracia participativa. También ha sido coordinador de textos docentes para la enseñanza. 


\section{Contextualización. Perspectivas del poder constituyente}

La vigente Constitución de la República de Cuba data de febrero de 1976, momento en que se refrendó popularmente. Ha sufrido cambios en 1978, 1992 y en 2002, y en la actualidad se encuentra de cara a una reforma. Desde los inicios de la Revolución cubana hasta la última reforma, los procesos de reforma constitucional han sido variados, y el elemento democrático ha tenido distinta intensidad.

En las pocas alusiones que se han hecho a la próxima reforma de la Constitución cubana no ha quedado claro cómo la ciudadanía intervendrá en el proceso ${ }^{1}$. De ahí que junto a la lógica pregunta ¿qué debe modificarse en la actual Constitución para atemperarla a los nuevos cambios económicos y responder así a un grupo de demandas que en el orden político, económico y social requieren ser evaluadas?, cabrían las reflexiones, igual de importantes: ¿incidirá la ciudadanía en la legitimación de la nueva reforma a la Constitución de 1976? y, de suceder, ¡a través de qué vías?

La última pregunta dependería, en principio, de la respuesta a la primera: se apelará a la ciudadanía en referendo, si los cambios que se propongan a la Constitución trascienden a los contenidos que exigen su uso, a partir de que el segundo párrafo del artículo 137 de la Constitución prevé:

Artículo 137. [...]

Si la reforma se refiere a la integración y facultades de la Asamblea Nacional del Poder Popular o de su Consejo de Estado o a derechos y deberes consagrados en la Constitución, requiere, además, la ratificación por el voto favorable de la mayoría de los ciudadanos con derecho electoral, en referendo convocado al efecto por la propia Asamblea.

Sin embargo, la duda se fundamenta en que los procesos de reforma constitucional acaecidos en Cuba, entre 1959 y 2002, no se han ajustado a la

1 Raúl Castro, Presidente de los Consejos de Estado y de Ministros, ha anunciado que la Constitución cubana se reformará. Ha dicho que por la trascendencia de algunos temas se requerirá el referendo, también que existe una comisión trabajando en la reforma e incluso que algunos cambios en el ordenamiento se pueden implementar paulatinamente y después ser introducidos en la Constitución. Véanse Informe Central al VI Congreso del Partido Comunista de Cuba. 16 de abril de 2011; Discursos en la clausura de la Primera Conferencia Nacional del Partido, 29 de enero de 2012 y, en las clausuras del IX Período Ordinario de Sesiones de la ANPP, 23 de julio de 2012, y de la Sesión de Constitución de la VII Legislatura de la ANPP en 2013. Todo ello demuestra una singular percepción sobre la supremacía constitucional y el elemento democrático que debe signar cualquier reforma de la constitución. 
lógica del principio de supremacía constitucional, que se expresa (aunque no únicamente) en los mandatos de las cláusulas de reforma; o sea, se ha puesto en tensión evidente la forma en la que se ha materializado la reforma de la carta magna y el mandato constitucional que prescribe cómo debe efectuarse la misma, a fin de garantizar su supremacía y defensa. Para ello, en ocasiones se han instrumentado formas de participación popular, al margen de lo prescrito en el procedimiento, para dotar de legitimidad al proceso en sí y al resultado político que se ha derivado del mismo.

A partir de lo anterior recobra valor la primera pregunta, teniendo en cuenta que con la reforma de 2002 se puso límites, no del todo definidos, a los contenidos constitucionales que pueden ser modificados, al introducirse una cláusula de intangibilidad en los siguientes términos:

Artículo 137. Esta Constitución solo puede ser reformada por la Asamblea Nacional del Poder Popular mediante acuerdo adoptado, en votación nominal, por una mayoría no inferior a las dos terceras partes del número total de sus integrantes, excepto en lo que se refiere al sistema político, social y económico, cuyo carácter irrevocable lo establece el artículo 3 del Capítulo I, y la prohibición de negociar bajo agresión, amenaza o coerción de una potencia extranjera, como se dispone en el artículo 11. $[\ldots]$

Con este trabajo se realizará un recorrido por las reformas constitucionales en Cuba entre 1959 y 2002, al efecto de verificar en cada una de ellas cómo se ha dado la correspondencia entre el proceso y el procedimiento de reforma previsto. Se tendrán en cuenta los contextos políticos, ideológicos e históricos en los que se han desarrollado, así como los posibles influjos constitucionales. Esto último en la actualidad recobra importancia, porque hoy el procedimiento de reforma de la Constitución cubana requiere de un rediseño, a tono con los presupuestos del nuevo constitucionalismo latinoamericano, en aras de su mayor democraticidad, para evitar en el futuro una ruptura constitucional.

El análisis histórico-constitucional de los procesos de reforma en Cuba se realizará por etapas, que se harán coincidir con el año en que se han efectuado, salvo la primera (1959-1973), que está comprendida dentro del "Período de Provisionalidad" (1959-1976) de la Revolución cubana, en el cual se efectuaron numerosas modificaciones a la base constitucional. En ninguna de estas etapas se abordarán aspectos relacionados con la estructura del Estado y sus órganos, derechos y deberes, y principios constitucionales, que hayan sido objeto de modificaciones, salvo cuando alguno haya trascendido a la concepción o puesta en práctica del mecanismo de reforma. 
En este trabajo, la variable "proceso de reforma" englobará los actos jurídicos y las decisiones políticas con trascendencia directa para la forma en que se modifica el texto constitucional, por lo que no será entendido en su sentido estrictamente normativo o legal, tal como sucede con el procedimiento de reforma, a la vez que integra las normas que especifican cómo puede modificarse una constitución.

El procedimiento puede desagregarse en tres fases principales: la iniciativa, la deliberación y la decisión final, por la cual se aprueba y adopta el proyecto, o se rechaza. Cada una de estas fases puede acarrear variantes y procederes jurídicos diversos ${ }^{2}$, asimismo permitirá realizar valoraciones de índole político-constitucional sobre la constitución formal, en la medida que se pueden anticipar valoraciones acerca del modo en que puede reformarse.

El proceso de reforma es más amplio. Puede llegar a comprender no solo determinaciones de orden constitucional, y no siempre circunscritas a las cláusulas de reforma, sino también determinaciones infraconstitucionales, por ejemplo, la ley que determina cómo se eligen los miembros del órgano constituyente, en la medida que esta puede determinar el nivel de paridad con que concurrirán las fuerzas políticas a integrar el órgano, o las decisiones del máximo garante de la carta magna respecto a la constitucionalidad de alguna cuestión relacionada con la reforma. Incluso puede comprender nociones que se ubican por encima de ella, como la que legitima la actuación del poder constituyente originario o prácticas políticas que, debiendo tener una específica apoyatura legal, pueden llegar a marginar lo prescrito, debido a una particular coyuntura política. Como dijese Pedro de $\mathrm{Vega}^{3}$ :

El estudio [...] de la normativa de la reforma, encierra una problemática mucho más rica y compleja que la que pudiera derivar del estricto análisis formal del procedimiento. Lo que conlleva que el planteamiento del mismo tenga que efectuarse desde un orden de consideraciones, políticas y jurídicas, que trascienden su dimensión adjetiva y meramente procesal.

Por su parte, "reforma de la constitución" se entenderá en su sentido más amplio, capaz de englobar cualquier modificación a su normativa, desde la enmienda (aditiva o supresora) hasta la creación de una nueva carta magna, mediante

2 Al margen de los límites temporal y geográfico con que hoy se pueda valorar, un buen ejercicio de sistematización de estos aspectos se puede encontrar en Quiroga Lavié (1991), pp. 236-241 y 243-244; más actual, igualmente circunscrito a Latinoamérica, Nogueira AlCAlA (2010), pp. 1261-1321.

3 De Vega (1985), p. 78. 
la convocatoria a una asamblea constituyente o cualquier otro proceder, lo que incluiría, como es lógico, los cambios parciales que se hagan a su contenido.

Esta última delimitación conceptual se sitúa al margen de la tesis de Schmitt, también acogida por parte de la doctrina constitucional ${ }^{4}$, para quien la reforma a la constitución no puede significar la destrucción de la misma, ni un atentado en contra de las decisiones políticas fundamentales plasmadas en ella, pues ello es facultad privativa del poder constituyente, solo puede implicar reformas parciales, adiciones, refundiciones, supresiones, etc., de las prescripciones legalconstitucionales que contiene ${ }^{5}$.

La reforma se configura como un mecanismo de "autodefensa" de la constitución, que garantiza su normatividad y supremacía. Esta garantía, que en un primer momento fue política, a fin de salvaguardar la carta magna de cualquier posibilidad de regresión al régimen que se superaba, evolucionó a una dimensión jurídica que facilitó su adecuación a las nuevas condiciones histórico-políticas que se imponían ${ }^{6}$. De ahí que trascendiera el mecanismo o procedimiento de reforma, y más adelante fuese importante, también, la valoración sobre su legitimidad democrática.

Lo último también ha tenido su propia evolución, mientras ha descansado en los paradigmas de la democracia representativa y del Estado de Derecho, se ha enfatizado en la legalidad del procedimiento de reforma y en el carácter extraordinario que este debía tener respecto al procedimiento legislativo ordinario (evolución de la constitución flexible a la rígida). Pero desde hace un tiempo la doctrina constitucional ha reconocido que la distinción hecha por Bryce acerca de las constituciones rígidas y flexibles ha perdido actualidad, incluso para el caso inglés que en un primer momento fue entendida como la típica constitución flexible 7 . Para Guastini dejó de ser un problema de distinción, para ser una cuestión de grado ${ }^{8}$.

4 También Zagrebelski (1988), citado por Nogueira Alcalá (2010), p. 1268. Ross desde una teoría de la norma y del ordenamiento jurídico, citado por Soto BarRientos, p. 402.

5 Sснмітт (1992), p. 119.

6 Pérez Royo (1997), pp. 168-172.

7 Así la vieron Hauriou (1927), p. 309, Duguit (1926), p. 520. Junto a otros autores, VANossi (2002), pp. 250 y 252, y De VeGA, pp. 51 y 52, han defendido la tesis de que para llegar a realizar una reforma constitucional en Inglaterra, el Parlamento requerirá una "señal de respuesta" del cuerpo electoral, a través de una nueva elección de ese órgano, cuya campaña deberá declarar el propósito de sancionar una ley modificatoria de la compleja constitución inglesa.

8 Guastini (2001), p. 189. 
No obstante, el resultado de un examen positivista del grado de rigidez, a partir del procedimiento prescrito para la reforma de la constitución, puede ser inexacto, ya que dependerá de otras variables político-constitucionales que dirán la última palabra acerca de cuán rígida, materialmente, es una constitución.

Desde el principio ( $\mathrm{y}$ a esto sirvieron de forma decisiva el pensamiento liberal francés y norteamericano), el poder constituyente se asoció al proceso-hecho político que desembocaba en una nueva constitución. Se había venido entendiendo que el ejercicio del poder constituyente originario quedaba circunscrito al poder de Revolución y a la creación de nuevo Estado (poder fundacional) 9 , esta última, a través de una asamblea o convención constituyente.

Así quedaba salvada la distinción entre el poder constituyente originario, indivisible, inalienable e ilimitado, tal como lo concibió Sieyès, y los poderes constituidos. De estos últimos se derivó el poder de reforma, el cual a través de un procedimiento, primero similar al ordinario (constituciones flexibles), después agravado (constituciones rígidas) podía modificar el contenido de la carta magna, incluso llegar a crear una nueva o "dinamitar" sus bases políticas fundamentales, momento en que se fusionaron poder constituyente y poderes constituidos. Esto último significaba un secuestro de la esencia primigenia de la soberanía como facultad y capacidad del cuerpo político (de la sociedad) de organizar su Estado y las relaciones políticas (de poder) que se desarrollarán entre sus miembros.

El paradigma de la democracia representativa y su señoreo redujeron también la forma de expresarse el poder constituyente, incluso en las constituciones que regularon la salida de la Asamblea Constituyente como resultado lógico-racional y tolerable del principio de representación, esta se encontraba a merced de la decisión de reforma de uno de los poderes constituidos. En otro sentido, eran las revoluciones o los golpes de estado las otras vías que justificaban la manifestación del poder constituyente.

Las transiciones de la Constitución de 1886 (con importantes reformas) a la de 1991 en Colombia; la de 1961 a la de 1999 en Venezuela, y la de 1998 a la de 2008 en Ecuador, son para Nogueira Alcalá ejemplos de cómo el poder constituyente originario "puede dar lugar a una nueva Constitución sin necesidad de uso de la fuerza o la violencia" 10 . Aunque para algunos significaron un regreso a las prístinas ideas del poder constituyente nacidas en Estados Unidos y en Francia ${ }^{11}$.

9 VANOSSI (2002), p. 241.

10 Nogueira Alcalá (2010), pp. 1265-1266.

11 Soto Barrientos (2014), p. 398. 
En estos casos, en los que la reforma total a las constituciones precedentes se realizó al margen del respectivo procedimiento establecido por ellas mismas, el cuerpo electoral terminó manifestándose como un poder contra ordinem, pero de manera legítima. Su legitimidad se fundamentó en que el titular del poder constituyente originario había sido invocado por uno de los poderes constituidos, sobre la base del principio de soberanía popular. Para ello se consultó al cuerpo electoral sobre si deseaba una nueva carta magna, cuyo asentimiento mayoritario trajo consigo la instauración de una Asamblea Constituyente, integrada por delegados electos directamente, que actuó en representación del poder constituyente originario, hasta llegar al referéndum, donde pudo expresarse nuevamente desde toda su potencia política y jurídica.

El nuevo constitucionalismo latinoamericano violentó la legalidad constitucional del procedimiento de reforma y contrapuso, desde la dimensión política de la soberanía, pero instrumentada jurídicamente ${ }^{12}$, el poder constituyente originario a los límites impuestos en la constitución que se deseaba destruir.

Desde mucho antes, el francés Maurice Hauriou refirió que la superlegalidad constitucional (forma en que llamó a la supremacía constitucional) estribaba, en parte, en la organización de una operación constituyente con un poder constituyente colocado por encima de los poderes ordinarios, y de un procedimiento especial de revisión que diera rigidez al texto ${ }^{13}$. Hauriou arremete contra la tesis del poder constituyente de Carre de Malberg y toma como base de examen el constitucionalismo europeo de la primera mitad del s. XIX, donde identifica cláusulas de reforma que se esfuerzan "en dificultar el establecimiento de constituciones revolucionarias, reforzando la continuidad legítima y oponiéndola a la discontinuidad", a través de procedimientos de revisión que permiten la elaboración de constituciones futuras, pero con la identidad política fundamental de la vigente, evitándose así "las ocasiones de desgarre"14.

El maestro de Toulouse sostuvo que el "establecimiento o la revisión de las constituciones es frecuentemente un hecho revolucionario en la forma, y lo es

12 La instrumentación jurídica de la soberanía popular en función de una asamblea constituyente tuvo un marcado protagonismo judicial, como fueron los casos de Colombia, Venezuela y Ecuador. Brewer Carías fundamentó in extenso por qué en el caso venezolano el poder constituyente (supremo e ilimitado) tuvo una desacertada configuración judicial. BREWER CARÍAS, pp. 33-96. Otra lectura del proceso constituyente es la que se dio en Cambio político y proceso constituyente en Venezuela, de Viciano Pastor y Martínez Dalmau, pp. 145-199.

13 Houriou (1927), pp. 309 y 310.

14 Houriou (1927), p. 312. 
siempre en el fondo", y que, ante la pretensión de garantizar la continuidad del Derecho del Estado, bajo el manto de legitimidad de la forma prevista para modificar la constitución, irrumpe la operación constituyente ${ }^{15}$.

Esto supondría la discontinuidad del Derecho del Estado y la participación de un poder mayoritario revolucionario respecto al ordinario de los poderes constituidos, pero lo más importante es que para él no significaba que se realizase sin derecho "como un puro hecho histórico", sino que se apelaba a un "derecho revolucionario que subsiste bajo la legitimidad del Derecho del Estado"16.

Los influjos del nuevo constitucionalismo latinoamericano, que se pueden enmarcar desde la Constitución colombiana de 1991 hasta la boliviana de 2009, se podrían verificar, entre otros aspectos, en una mayor influencia del principio democrático en el principio estructural de la representación; el primero de ellos de naturaleza deontológica y verificable en buena medida en las formas de participación directa. Esto también ha trascendido al nivel de participación (y decisión) del pueblo en la reforma de la constitución. Con esto no se quiere afirmar que el uso del referendo o la iniciativa de reforma ha sido un fenómeno propio de los modelos constitucionales que se han inscrito en este movimiento constitucional. Existen ejemplos, incluso históricos, de cláusulas de reformas que regulan estos mecanismos de participación popular para modificar la constitución, como el de la efímera Constitución francesa de 1793 o de la Constitución suiza de 1848 que prevé la iniciativa popular para su reforma ${ }^{17}$.

Para Pedro de Vega, quien se apoya en la tesis de Loewenstein, con el uso de los mecanismos de democracia directa o semidirecta se ha tratado de dotar de mayor legitimidad a la reforma, que junto a la lógica del principio de tripartición de poderes, ayudaría a obtener un amplio consenso. A lo primero tributaría la participación del pueblo organizado como electorado en la iniciativa o en la ratificación ${ }^{18}$; con lo segundo se evitaría "la posibilidad de un secuestro permanente del sistema constitucional, cuyas exigencias de renovación no

\footnotetext{
15 Houriou (1927), p. 312.

16 Houriou (1927), p. 311.

17 De Vega menciona los ejemplos de las emblemáticas constituciones de Austria de 1920 y de Weimar de 1919, De Vega (1985), p. 106. En el contexto latinoamericano, el estudio de Nogueira Alcalá arrojó que varias constituciones latinoamericanas reconocían la iniciativa popular de reforma constitucional y el referendo antes de 1991 (año que se está tomando como referencia para marcar el inicio del movimiento del nuevo constitucionalismo latinoamericano). Nogueira Alcalá (2010), p. 1273.
}

18 De Vega (1985), p. 90. 
vendrían condicionadas tanto por las necesidades y urgencias que la historia y la realidad objetivamente impusieran, como por los requerimientos particulares y las necesidades apreciadas por el único poder en que se hiciera recaer la función de la reforma"19.

Pero es justo decir que con las últimas constituciones de Colombia, Venezuela, Ecuador y Bolivia, esta noción se ha ido ampliando, a fin de asegurar mayor influencia del titular del poder constituyente en la reforma constitucional (como cierre de la evolución de la constitución rígida a la rígida democrática). Con ello, al amparo del principio de soberanía popular, además de preverse la consulta popular o referendo, o la iniciativa ciudadana, en la enmienda y la reforma parcial, se ha regulado la intervención del cuerpo electoral en todas las fases del proceso de creación de una nueva constitución.

La tesis aceptada de que el poder constituyente, cuando aprueba un orden constitucional establece además los pasos para su transformación en el procedimiento de reforma y se sitúa "como fuerza externa al sistema y voluntariamente desaparece de la mecánica constitucional"20, ha quedado "válida" para aquellas constituciones que prevén mecanismos de reforma con un protagonismo de poderes constituidos, que se transforman en poder revisor de la constitución, gracias a un procedimiento agravado o a su actuar de conjunto en función del cambio constitucional ${ }^{21}$.

Pero son los artículos 444 y el 411 en su primer párrafo de la Constitución de Ecuador de 2008 y Bolivia de 2009, los que legalizan la expresión máxima del poder constituyente originario (derivado por los límites del procedimiento). En esos preceptos se reconoce que la iniciativa de convocar a una asamblea constituyente, incluso cuando sea por el pueblo, debe ser sometida a consulta popular, además de que la ciudadanía elegirá directamente a los delegados a la asamblea constituyente y después podrá aprobar o rechazar en referendo el proyecto de carta magna ${ }^{22}$. El primero de estos pasos (el de decidir una nueva constitución)

19 De VeGA (1985), p. 90.

20 De Vega (1985), p. 109.

21 Se está haciendo referencia a los procedimientos de reforma adoptados únicamente por órganos representativos permanentes del Estado. Sobre este particular, consúltese la sistematización que hace Nogueira Alcalá de las constituciones latinoamericanas que reconocen esta modalidad. NogueIra AlCALÁ (2010), pp. 1275-1279.

22 Cfr. Constitución de la República de Ecuador, 2008, y Constitución Política del Estado de Bolivia, 2009. 
es lo que Schmitt denominó ejercicio del poder constituyente mediante el acto de la decisión política fundamental ${ }^{23}$.

A partir de las cláusulas de reforma de estas constituciones, se configuró una fórmula legal que potencialmente disminuye las posibilidades de ruptura constitucional. Todo esto a la postre debe funcionar como aporte fundante con bases definidas en un pensamiento liberal-revolucionario, pero con claros efectos fundacionales de una nueva manera de concebir la reforma de la constitución.

Sobre la base de la identidad entre pueblo y poder constituyente, a tono con la afirmación de Nogueira Alcalá de que la "concepción de Poder Constituyente admite únicamente al pueblo en cuanto cuerpo político de la sociedad como sujeto titular de ella" 24 . Tesis que tiene su origen en Sieyès, pero que terminó incompleta al quedar la titularidad en la nación, una identidad política más que un ser político. Interesará entonces saber, desde una nueva visión promovida por el nuevo constitucionalismo latinoamericano, cuándo puede o debe actuar el poder constituyente, su permanencia o transformación normativa (¡cuáles son las manifestaciones jurídicas de su actuación?), qué otros poderes pueden actuar sobre la constitución y cuáles son los límites de todos.

Si desde una lógica semántica constituir es crear o fundar algo, mientras que reformar es cambiar lo creado o constituido, la categoría poder constituyente podría quedar circunscrita a la facultad que tiene el soberano, o sea el pueblo, de darse una nueva constitución o, lo que puede significar lo mismo, destruir las bases político-axiológicas que sustentan el orden político del Estado.

Pero también hay evidencias del titular del poder constitiyente en la posibilidad que tiene el cuerpo electoral de legitimar o rechazar las propuestas del poder revisor de la constitución, al preverse referendos preceptivos dentro de los mecanismos de reforma, lo que le permitiría actuar como un contrapoder y contribuir de alguna manera a la continuidad constitucional; o en la iniciativa popular de enmienda o reforma parcial (acción de equilibrio); o como poder autosuficiente, capaz de expresarse en toda su potencia, al poseer la iniciativa de reformar totalmente la constitución (o de estar protegido por la exigencia de consultársele en caso que la iniciativa nazca de uno de los poderes constituidos), estar facultado para elegir directamente a los que integrarán el órgano especial que concebirá el nuevo texto, y de decidir en referendo, todo ello como partes

23 SCHMitT (1992), p. 108.

24 Nogueira Alcalá (2010), p. 1263. 
conexas de un único mecanismo institucionalizado por la propia constitución. $\mathrm{Si}$ "poder constituyente es la voluntad política cuya fuerza o autoridad es capaz de adoptar la concreta decisión de conjunto sobre modo y forma de la propia existencia política" 25 , su verdadera expresión radica en su autosuficiencia, con el único límite material de la imposibilidad de deliberar la constitución como unidad política subjetiva, para lo que se valdría de la asamblea constituyente, elegida directamente por él. Con ello se ha tratado de asegurar la constancia normativa (concentrada) del poder constituyente originario o, ciertamente, su continuidad.

Esta última tesis permite una relectura analítica a partir del examen de los procedimientos de reforma de las constituciones de Ecuador (2008) y Bolivia (2009), en el sentido de que a la reforma de la constitución pueden concurrir varios tipos de poderes: el poder revisor o de reforma de la constitución, el poder constituyente derivado y el poder constituyente originario. El primero podrá llevar a cabo modificaciones a la constitución de forma parcial o puntual a través de enmiendas, pero tendrá que respetar el procedimiento descrito en las cláusulas de reforma y no podrá atentar contra los límites a la reforma dispuestos en las cláusulas de intangibilidad o cláusulas pétreas, como también se le conocen.

El segundo actuará como reflejo más inmediato del poder constituyente originario. Podrá tener diferentes expresiones, tal como se comentó en el párrafo anterior. Estará facultado para reformar totalmente la constitución, y bajo la lógica del principio "quien puede lo mucho puede lo poco", podrá incidir en las demás formas de modificar la constitución, donde tendrá que seguir el procedimiento establecido en ella misma, al igual que en la reforma total de la carta magna. Como auténtico reflejo del poder constituyente originario siempre tendrá la capacidad de autodeterminar el orden político que desea para sí a través del Estado como organización política, y como poder ilimitado podrá destruir la constitución desde sus bases político-axiológicas que la sustentan, pero respetando el procedimiento, lo que constituye su único límite. El procedimiento de reforma opera como un límite lógico absoluto, un límite de razón fundado sobre exigencias de lógica abstracta ${ }^{26}$.

Por su parte, el poder constituyente originario, al no poseer más límites que él mismo, quedará reservado para cuando determinadas circunstancias políticas conlleven a que el poder constituyente derivado no pueda manifestar toda su potencia y fuerza derogatoria, como pueden ser razones de "realismo político"

25 SсHмiтt (1992), pp. 93 у 94.

26 Crisafulli (1970), p. 101. 
(sutil o no ejercicio de un poder antidemocrático) que impidan que el pueblo pueda emprender acciones encaminadas a la reforma, por ejemplo, no puede validar la iniciativa. Como es lógico, tendrá reservado su poder de revolución o de creación de un nuevo Estado. Ante la insuficiencia de la dimensión jurídica de la soberanía, el poder constituyente originario tendrá que apelar a la dimensión política de esta.

La relación entre la soberanía popular y la supremacía constitucional debe tener en cuenta las dos dimensiones en las que se proyecta la primera. La dimensión jurídica de la soberanía popular, tal como dice De Vega, no puede negar su dimensión política, que en los marcos de la reforma de la constitución no "debe ni puede implicar la negación real del pueblo como auténtico poder constituyente"27. De manera clarividente, el profesor Sánchez Viamonte llamó la atención sobre que todavía en la mitad del s. XX se venía arrastrando un concepto de soberanía legado por el liberalismo decimonónico, de sustrato monárquico, y conjugó acertadamente las dimensiones política y jurídica de la soberanía:

Para la república democrática no hay ni puede haber más soberanía interna o externa que la popular, de tal manera que, desde el punto de vista político, soberanía es la voluntad de la mayoría. Pero como la república democrática es el Estado de derecho, es decir, sometido al derecho en la totalidad de su existencia y manifestación, la validez de esa expresión de voluntad mayoritaria depende de su conformidad con el ordenamiento jurídico. En esa forma se produce la necesaria subordinación de la soberanía política a la soberanía jurídica, que se confunde con el problema de la vigencia constitucional y de la supremacía de la Constitución ${ }^{28}$.

La soberanía es capacidad de autodeterminación, y el poder constituyente es la máxima expresión de la misma. La soberanía popular, principio declarado por la propia carta magna, requiere sus propias reafirmaciones normativas a ese rango, que se ponen en evidencia a través de las instituciones de democracia semidirecta (referéndum, iniciativa legislativa popular, recall, plebiscito), del procedimiento democrático de reforma de la constitución e incluso del reconocimiento constitucional del derecho a la resistencia, que a la postre no solo expresan la voluntad popular, sino el cauce por el cual esta puede manifestarse legalmente 29 .

7 De Vega (1985), p. 108.

28 Sánchez Viamonte (1957), pp. 58 y 59.

29 Sánchez Viamonte (1957), p. 59. 
Nogueira Alcalá sostiene que "los procedimientos de reforma constitucional establecidos en los textos constitucionales tienen un carácter obligatorio, por lo cual toda reforma constitucional realizada por procedimientos no previstos en la Constitución está viciada de inconstitucionalidad”. Lo que es cierto, pero si apelar a cualquier manifestación del titular del poder constituyente, por ejemplo, en referendo, es expresión legal del principio de soberanía popular, cabría cuestionarse si este principio se integra implícitamente a las cláusulas de reforma $y$, por lo tanto, un referendo aprobatorio de la reforma constitucional que no se encuentre previsto en las cláusulas de reforma es legal o cuando menos legítimo.

Veamos a continuación cómo a partir de 1959 se han concretado los procesos de reforma en Cuba, así como los altos y bajos del elemento democrático en los procedimientos de reforma, debido a determinadas influencias constitucionales y conveniencias políticas contextuales.

$$
\text { II. (1959-1963)-197330: }
$$

\section{¿CONTINUIDAD, ENMIENDAS O LEYES FUNDAMENTALES DE LA REVOLUCIÓN?}

Al triunfar la Revolución cubana en 1959, estaba vigente la Constitución de 1940, texto progresista con marcado carácter garantista, que se adelantaba en algunos aspectos a los textos que se consideran iniciadores del constitucionalismo social $^{31}$. La normatividad de la Constitución del 40 -como también se le conoceestuvo limitada, su legislación complementaria fue tardía e incompleta, además, durante el gobierno de Fulgencio Batista quedaron suspendidas sus garantías entre 1952-1954.

Para ese momento, el procedimiento de reforma era uno de los más democráticos de América Latina. La cláusula de reforma preveía la iniciativa popular de reforma constitucional, ya fuese específica, parcial o total, la elección directa para la conformación de una asamblea plebiscitaria y el referendo. La iniciativa

30 Se asume 1973 como el último año en que se realizó una reforma a la LF 1959, antes de la promulgación de la Constitución de 1976. Cfr. Ley de Reforma Constitucional, 21 junio 1973, que modificó los preceptos relacionados con los tribunales y la fiscalía, así como el artículo 15 relativo a la ciudadanía.

31 En materia de derechos fundamentales, por ejemplo, los artículos 48 (enseñanza gratuita, excepto para los niveles pre y universitarios); 49 (voluntad del Estado para eliminar el analfabetismo a través de un sistema de escuelas para adultos); 60 y 65 (derecho al trabajo y a la seguridad social, respectivamente) y 79 (compromiso del Estado de fomentar la creación de viviendas baratas para obreros). Estos, junto a otros artículos, como el 20 (principio de no discriminación por cualquier motivo); el 55 (laicidad de la enseñanza oficial) y el 90 (proscripción del latifundio). Ley № 1, 1940. 
popular de reforma que no fuese total conllevaba directamente la convocatoria a referendo, lo que significaba la expresión directa del cuerpo electoral; también si la iniciativa tenía que ver con una reelección prohibida constitucionalmente, en la que mediaba la aprobación de las 3/4 partes del Congreso.

En caso que la iniciativa popular fuese para la reforma total o se limitara la soberanía nacional, la forma de gobierno o los artículos 22, 23 y 2432 , se convocaba a elecciones de la asamblea plebiscitaria que decidiría sobre la reforma propuesta. Esta última solución era muestra de la marcada influencia del modelo norteamericano, ya que se practicaba en la mayoría de los estados de la federación.

Los artículos 285 y 286 regularon al Congreso como un poder revisor o de reforma de la Constitución, que requería de una mayoría agravada a lograr por sus dos cuerpos colegisladores, reunidos de conjunto, y que tenía como límite el poder iniciar la reforma total de la Constitución, sin participar en ella y, por ende, sin decidirla.

El nuevo poder revolucionario reafirmó la vigencia de la Constitución del 40 "como norma fundamental estructuradora del Estado de derecho" que caracterizaría el desenvolvimiento del Gobierno y la nación ${ }^{33}$. En esa misma acta acotó: "[...] sin perjuicio de las modificaciones que de ella acuerde el Gobierno Provisional para viabilizar el cumplimiento de los postulados de la Revolución hasta la promulgación de la Ley Fundamental" 34 , formalizando así el primer cambio a la Constitución del 40, al margen de su procedimiento de reforma.

El acta legitimó al nuevo Consejo de Ministros (revolucionario) como único órgano de gobierno con potestad legislativa y de reforma de la Constitución del 40, tal como se materializó antes de la promulgación de la Ley Fundamental de 1959 (LF 1959) 35 .

32 Estos se referían a la intangibilidad de las obligaciones contractuales por los actos del poder público (art. 22); a la prohibición de la confiscación de bienes y requisitos de su excepcionalidad (art. 24), y al reconocimiento de la propiedad privada y su función social, límites a la misma por necesidad pública e interés social (art. 87), Ley No 1, 1940.

33 Cfr. Acta de Constitución del Gobierno Revolucionario en BuCH y SuÁrez (2004), pp. 172-174.

34 Ibídem.

35 Entre los días 3 de enero, fecha en que se redactó el Acta de Constitución del Gobierno Revolucionario, que reafirmó la vigencia de la Constitución del 40, y 7 de febrero, momento en que entró en vigor la LF 1959, la Constitución del 40 sufrió modificaciones en su contenido. Las reformas estuvieron encaminadas a afianzar el poder revolucionario, reprimir las conductas o revocar el status de las personas vinculadas con el régimen anterior de Batista. 
Conteste con la tesis de Jellinek, según la cual "cada revolución triunfante crea un derecho nuevo" ${ }^{36}$, y de Schmitt, para quien "es inconcebible que una Constitución nueva, es decir, una nueva decisión política fundamental, se subordine a una Constitución anterior y se haga dependiente de ella"37, la Revolución cubana fue fuente de derecho y, a la vez, fuente de una novísima constitucionalidad en Cuba. Si el procedimiento de reforma es entendido como uno de los límites lógicos a la reforma de la constitución, sobre el cual solo puede actuar el poder constituyente, sin lugar a dudas, el gobierno revolucionario se estaba subrogando en su lugar y grado.

Ciertamente el gobierno revolucionario no estaba preparado para un proceso constituyente a tono con lo pautado en los párrafos antepenúltimo y penúltimo del artículo 286, a partir de los cuales tendría que convocar a elecciones para delegados a una asamblea plebiscitaria y se impedía que los congresistas pudieran ser delegados, asegurando así el carácter originario de la misma. Es válido aclarar que si bien el Congreso había quedado disuelto, y en su lugar se había subrogado el nuevo Consejo de Ministros (revolucionario), el artículo 286 podía haberse empleado mutatis mutandis.

Un proceso constituyente a tenor de lo preceptuado por la Constitución del 40, hubiese significado, por un lado, descartar la participación en la asamblea de importantes figuras revolucionarias que ocupaban cargos en el nuevo Consejo de Ministros; por otro lado, se atentaría contra la unidad de las fuerzas políticas revolucionarias, que colisionarían criterios en una asamblea constituyente. La unidad de acción revolucionaria y de objetivo político de las principales fuerzas que se oponían al régimen político imperante antes de 1959, necesariamente no podía traducirse en unidad de proyecto político, al efecto de concebir una nación bajo la égida del progreso y la inclusión social, el desarrollo económico y la soberanía política.

El 7 de febrero de 1959 se proclamó la Ley Fundamental de 1959 (LF 1959). La decisión de que esta integrase la mayoría de los preceptos de la parte dogmática de la Constitución del 40, pero con una nueva organización del aparato estatal, capaz de afrontar operativamente el nuevo período revolucionario, pretendía la continuidad constitucional. Esta sucesión constitucional puso en evidencia lo que afirma Zúñiga Urbina ${ }^{38}$ de que:

36 JeLLineK (1991), p. 9.

37 Sснмiтt (1992), pp. 104-105.

38 Zúníiga Urbina (2013), p. 520. 
El "derecho constitucional transitorio" sirve de nexo entre dos órdenes constitucionales que se suceden temporalmente, uno fenece y otro nace, permitiendo así cubrir con un manto de "legitimidad" o "juridicidad" al nexo con el pasado, a la evidente, notoria y necesaria facticidad del recurso al poder constituyente originario.

Desde un primer momento, el poder revolucionario desechó la rigidez constitucional del texto del 40, así como el elemento democrático presente en ella, a la vez que, por un lado, el mismo órgano que tenía la facultad para dictar las leyes, o sea el Consejo de Ministros, pudo modificar, primero, a la propia Constitución del 40 y, después a la LF 1959, solo que en este caso con un procedimiento formalmente agravado y, por otro, se proscribió la iniciativa de reforma, el referendo y la elección directa de los miembros de la Asamblea Plebiscitaria. El titular del poder constituyente quedaba así completamente anulado.

La continuidad constitucional no restituyó las cláusulas de reforma de la Constitución del 40. El procedimiento recogido en el artículo 232 de la LF 1959 no reprodujo los artículos 285 y 286 de la Constitución del 40, sino el tenor del artículo 257 de los estatutos constitucionales que Batista promulgase en abril de 1952, en ocasión del Golpe de Estado del 10 de marzo de ese año ${ }^{39}$.

La supresión de la LF 1959 para dar paso a la Constitución de 1976, desbordó lo prescrito por la norma, a través de un procedimiento que marginó al mecanismo de reforma instituido e implicó al pueblo en la concepción de la nueva carta magna, de una forma sui generis respecto a los patrones del constitucionalismo liberal, tal como se verá en el epígrafe siguiente.

El derecho constitucional transitorio no se agotó en la LF 1959, ya que esta fue enmendada por las leyes de nacionalización (se excluyen las declaraciones de La Habana por no tener fin nacionalizador), siguiendo el antecedente sentado por la Constitución norteamericana ${ }^{40}$. Villabella Armengol tiene además en cuenta las mutaciones, a raíz de decisiones políticas refrendadas popularmente, como la Primera Declaración de La Habana, en la medida que significaron nuevos principios, convenciones y prácticas con rango constitucional ${ }^{41}$.

39 El artículo 257 establecía que la Ley Constitucional podría ser reformada por el Consejo de Ministros con un quórum de las dos terceras partes de sus miembros. Ley Constitucional para la República de Cuba, G.O. No 32, 4 de abril de 1952.

40 Vega Vega (1997), p. 104.

41 Villabella Armengol (2009), p. 78. 
Ambas consideraciones referidas a cómo se fue modificando continuamente la LF 1959 hasta la promulgación de la vigente Constitución en 1976, desde el punto de vista técnico, sometería esta sucesión de actos constituyentes a una lógica con moldes técnicamente liberales, que se vuelven inconsistentes cuando se diferencian las modificaciones que se hicieron a la LF 1959 en forma de adiciones que no tocaron la letra del texto y cambiaron su espíritu, de otras que fueron cambios en su contenido y se extendieron hasta 1973, como resultado de la progresiva institucionalización del Estado cubano e, incluso, algunas que aunque fueron auténticas leyes de nacionalización, se ampararon en la propia LF 1959.

El proceso constituyente cubano de 1959 a $1963^{42}$ no fue resultado de un único acto constituyente (la promulgación de la LF 1959 por acuerdo del Consejo de Ministros) que sufrió diversas reformas, sino más bien se debió a una pluralidad de actos constituyentes (leyes y decisiones político-constitucionales), que terminaron complementando el orden constitucional que se pretendía instituir para ese período, y que había sido iniciado desde el mismo momento en que el gobierno revolucionario traspasó uno de los límites de la Constitución del 40, al modificar su procedimiento, en el Acta de Constitución del gobierno revolucionario. Consciente o inconscientemente se acogió un concepto relativo de constitución ${ }^{43}$, que sacrificó toda distinción objetiva y de contenido que se diseminó en leyes constitucionales distintas e incluso formalmente variadas.

El poder constituyente fue el gobierno revolucionario, representando por el naciente Consejo de Ministros. En ocasiones, a través del l'apel au peuple, trató de "sobrelegitimarse" como poder constituyente soberano. Tal es el caso de las Declaraciones de La Habana, donde el pueblo en manifestaciones espontáneas dijo sí a principios (antimperialismo, no alineamiento, socialismo, antimonopolio, preeminencia de los derechos sociales) que se integraron a la Constitución y a la práctica constitucional de ese período.

\section{1976: LA ELABORACIÓN DE LA CONSTITUCIÓN BAJO LOS FUNDAMENTOS} LENINISTAS Y LA EXPERIENCIA CONSTITUCIONAL DE LOS PAÍSES SOCIALISTAS

La celebración del Primer Congreso del Partido Comunista de Cuba en 1975 consolidó la institucionalización política del país, sobre todo en lo referente a

42 Posterior a 1963 hasta 1973 se siguió modificando la LF 1959, pero sin afectar la esencia del texto.

43 Sснмiтt (1992), p. 37. 
dos definiciones trascendentes: una, el Partido Comunista sería la fuerza política que aglutinaría y transformaría a las diversas instituciones y organizaciones que habían participado en la institucionalización del Estado, durante el Período de Provisionalidad y, por lo tanto, fungiría como fuerza política dirigente del aparato estatal; dos, el marxismo-leninismo sería la ideología que informaría la construcción de la sociedad socialista cubana.

En octubre de 1974, por acuerdo del Buró Político del Comité Central del PCC y del Comité Ejecutivo del Consejo de Ministros, se nombró una comisión integrada por miembros del Buró Político y del gobierno, que tendría la responsabilidad de preparar y redactar el anteproyecto de constitución. El acuerdo describía un procedimiento singular para la tradición constitucional cubana.

Ya para ese entonces el modelo político soviético tenía una notable influencia sobre la dirección política en Cuba. El modelo soviético había alcanzado una considerable expansión por los países socialistas de Europa del Este, excepto Yugoslavia. La unidad de poder fue uno de los fundamentos del modelo político socialista, que se había heredado directamente de las ideas leninistas y que tuvo su primera expresión en la Constitución soviética de 1917, que buscó maximizar el poder soberano de los soviets.

The separation of power was another new problem in the course of framing the construction. In this respect, too, the principle of the sovereign power of the Soviet could not be restricted and therefore it was not possible to adopt any bourgeois form of the separation of power between the legislative and the executive branches. Yet, the aforesaid requirement of accuracy and coordination did not allow any continued uncertainti in the separation of powers ${ }^{44}$.

La aceptación de un poder constituyente que se exprese en una asamblea soberana elegida directamente por el pueblo podía producir una contradicción de intereses entre el órgano legislativo que representaba el poder soberano del pueblo y el nuevo órgano especial que tendría como encargo elaborar la nueva constitución.

Pero si “¿Qué es el Tercer Estado?”, del abate Sieyés, sentó las bases políticofilosóficas del poder constituyente para el liberalismo constitucional, la "Tesis sobre la Asamblea Constituyente" de Lenin se erigió como el fundamento políticofilosófico para proscribir las asambleas constituyentes como formas legítimas para crear la constitución del estado socialista naciente. En ese breve documento

44 BIHARI (1979), p. 34. 
Lenin planteó razones de índole práctica y política ${ }^{45}$ que justificaban por qué se desechaba la reivindicación de la convocatoria a una asamblea constituyente, que en su momento hiciera la socialdemocracia revolucionaria. Bajo la premisa de que la república de los soviets es una forma de democracia superior a la república ordinaria, con su Asamblea Constituyente, quedó proscrito del constitucionalismo socialista este mecanismo formalmente democrático ${ }^{46}$.

El proceso constitucional cubano de 1976 llegó con la premisa socialista de no a una asamblea constituyente, aunque -como se vio- ya había descartado este mecanismo en 1959. Para el pensamiento constitucional socialista no era un problema que el poder constituyente se manifestara, a través de la elección directa de delegados a una asamblea constituyente y del referendo, sino lograr un proceso constitucional con la participación popular, aunque en algunos aspectos coincidieran ambas concepciones.

De ahí que el proceso de elaboración de la Constitución cubana de 1976 diera un rol importante al Partido Comunista de Cuba y al gobierno, a través de la creación de una Comisión Redactora Conjunta formada por miembros de ambos ${ }^{47}$, similar al proceso de elaboración de la Constitución soviética en $1936^{48}$ y la checa en 1960, donde el Partido Comunista tuvo una notable par-

45 En las tesis 4 y 5 Lenin planteó los problemas de representatividad que podían traer consigo las listas presentadas a mediados de octubre de 1917, que impedían que la Asamblea Constituyente fuese una expresión exacta de la voluntad del pueblo en general y de las masas trabajadoras en particular. En la tesis 6 adujo otro problema práctico: el hecho de que las elecciones a la Asamblea Constituyente se habían celebrado en un momento anterior a la Revolución de octubre, por lo que el pueblo no podía conocer toda su extensión y alcance. LENIN (1960), pp. 548-549 (tomo 2).

46 Existen otros dos documentos que complementan las tesis sobre la Asamblea Constituyente, aunque sin novedad de criterios. Estos son la parte denominada "La Asamblea Constituyente y la República Soviética" dentro de la Revolución proletaria y el renegado Kautsky. En él Lenin responde a Kautsky, quien alude que la disolución de la Asamblea Constituyente se debe a que el partido de los bolcheviques no tendría mayoría. Lenin (1960), pp. 99-106 (tomo 3); y el Proyecto de Decreto disolviendo la Asamblea Constituyente. Lenin (1960), pp. 574-575 (tomo 2).

47 La comisión redactora estaba ligada a los poderes constituidos desde su nombramiento, cumpliría un encargo político a la vez que se limitaría a aprobar las líneas generales del anteproyecto, las que a la par debían tener en cuenta las determinaciones de contenido que se relacionaron en el propio acuerdo, pues del séptimo al décimo considerando del acuerdo del Buró Político y del Comité Ejecutivo, se relacionó una serie de "orientaciones" que "sin entrar en detalles, ni agotar la exposición de los distintos aspectos" deberían ser tenidos en cuenta -y así se hizo- al efecto de ser incluidos en el anteproyecto. Acuerdo del Buró Político del Comité Central del PCC y del Comité Ejecutivo del Consejo de Ministros, 23 de octubre de 1974.

48 El proceso de la constitución soviética de 1936 lo describe García Pelayo en su Derecho Constitucional Comparado, García Pelayo (1961), p. 584. 
ticipación y el proyecto se sometió a discusión popular ${ }^{49}$. Por otra parte, de la experiencia búlgara en la elaboración de su carta magna en 1971, fue tomado el referendo aprobatorio.

La consulta popular, que también incluyó la Ley de Tránsito Constitucional, terminó con 5.473 .534 de votos que aprobaban la nueva constitución, frente a 54.070 que la rechazaron; participaron 5.602.973 cubanos. Algunos autores han minimizado la trascendencia constitucional del proceso de elaboración de la Constitución de 1976 arguyendo que el mismo se dio en un ambiente autoritario $^{50}$ o con falta de libertades públicas ${ }^{51}$.

La cláusula de reforma en virtud de la nueva constitución, contenida en el Capítulo XII, en su único artículo (141), de algún modo traía de regreso el espíritu democratizador de la Constitución del 40, que había sacrificado la LF 1959. El artículo $141^{52}$ quedó redactado de la siguiente manera:

Artículo 141. Esta Constitución solo puede ser reformada, total o parcialmente, por la Asamblea Nacional del Poder Popular mediante acuerdo adoptado, en votación nominal, por una mayoría no inferior a las dos terceras partes del número total de sus integrantes.

Si la reforma es total o se refiere a la integración y facultades de la Asamblea Nacional del Poder Popular o de su Consejo de Estado o a derechos y deberes consagrados en la Constitución, requiere, además, la ratificación por el voto favorable de la mayoría de los ciudadanos con derecho electoral, en referendo convocado al efecto por la propia Asamblea.

Con él se previó un mecanismo de reforma semiflexible en manos de la Asamblea Nacional del Poder Popular (ANPP en adelante), y uno rígido para determinados supuestos, en los que se previó el referendo.

49 En el Informe del Comité Central del PCC, presentado por Fidel Castro al Primer Congreso del PCC sostuvo: "Alrededor de 6 millones 200 mil personas tomaron parte en la discusión del proyecto, agrupadas en las organizaciones y organismos del Partido, los Sindicatos, los CDR, la FMC, la ANAP, la FEU, la FEEM, las unidades militares y nuestras misiones en el exterior. [...] Cinco millones y medio votaron a favor de mantener el proyecto sin modificaciones: 16 mil personas propusieron diferentes modificaciones y adiciones, que fueron respaldadas por los votos de algo más de 600 mil participantes en las diversas asambleas [...]". Fragmentos del Informe del CC del PCC, presentado por el Primer Secretario del PCC y Primer Ministro del Gobierno Revolucionario, Comandante en Jefe Fidel Castro, al Primer Congreso del P.C.C, relativo a la nueva Constitución de la República. Revista Cubana de Derecho, pp. 59-60.

50 Vergottini (2009), p. 146.

51 Asensi Sabater (1996), p. 63.

52 Constitución de la República y Ley de Tránsito Constitucional, 24 febrero 1976. 
Se puede constatar la influencia que recibió la Constitución cubana de las constituciones socialistas, especialmente de la búlgara y la soviética; sin embargo, la previsión constitucional del referendo para determinados supuestos de reforma, en las constituciones socialistas solo tenía los precedentes de la Constitución Democrática Alemana de 1949 (artículo 83) y de la República Socialista Federativa de Yugoslavia de 1963. Esta última preveía en su artículo 214 un referéndum de ultima ratio, en caso que después de aprobado el proyecto por los Consejos Federal y de las Nacionalidades, no se lograba que otros tres consejos, como mínimo, aprobasen el proyecto.

La mayoría de los procedimientos de reforma de la constitución en los países socialistas de Europa hacían recaer el poder constituyente en el órgano legislativo supremo -justo una de las críticas que se le hacía al liberalismo constitucional del s. XIX y primera mitad del s. XX- que tenía la facultad de reformar la constitución sin límites. Las formas democráticas para legitimar popularmente la reforma (referendo, iniciativa popular) quedaron reducidas a los pocos ejemplos que se mencionaron en el párrafo anterior. Contrariamente, en la mayoría de esas constituciones se constataba una "hiperbolización normativa" 53 del principio de soberanía popular, que en lo referente a que el pueblo conservase su capacidad de determinar las decisiones políticas fundamentales del orden político y social, solo tenía un efecto declarativo.

Vergottini destaca cómo, de las constituciones socialistas, solo la de Alemania oriental (1965), la búlgara (1971) y la cubana (1976) fueron refrendadas popularmente, procesos al que imputó una naturaleza plebiscitaria ${ }^{54}$. Sin embargo, ninguna de esas constituciones europeas prescribió el referendo dentro del mecanismo de reforma.

\section{1992: LA SEGUNDA REFORMA A LA CONSTITUCión DE $19766^{55}$. EL SOSLAYO DEL ELEMENTO DEMOCRÁTICO}

La reforma de 1992 fue la conclusión de un iter político que tuvo como precedente el IV Congreso del PCC celebrado el año anterior, los resultados obtenidos

\footnotetext{
53 Algunos ejemplos de esto son la Constitución búlgara de 1971, que declaraba en su artículo 3: En la República Popular de Bulgaria todo el poder emana del pueblo y pertenece al pueblo; la rumana de 1965, que en su artículo 2 proclamó: En la República Socialista de Rumania todo el poder pertenece al pueblo, libre y dueño de sus destinos.

54 Vergottini (2009), p. 146.

55 En el recorrido histórico de este trabajo se obviará la reforma realizada a la Constitución en 1978, mediante la cual se cambió el nombre a la Isla de Pinos por el de Isla de la Juventud. Ley de Reforma Constitucional, 29 junio 1978.
} 
durante el inconcluso proceso de "rectificación de errores y tendencias negativas" (1986-1989), así como el perfeccionamiento de los órganos del poder popular -esta vez con la naciente experiencia de los consejos populares-. Sin embargo, la nueva situación internacional que definió el derrumbe del campo socialista (1989-1990) y la disolución de la Unión de Repúblicas Socialistas Soviéticas (URSS) en 1991, fue lo que la catalizó e incluso determinó inhibir el elemento democrático del procedimiento de reforma.

En esta ocasión, paradójicamente, la tensión versó sobre el elemento legitimador del cambio: el uso del referendo. La legitimidad democrático-popular que se había promovido con la Constitución de 1976, primero como medio de legitimación del proceso y después como elemento democratizador del mecanismo de reforma prescrito, sufrió un retroceso. El referendo no fue complementado por la discusión popular, como en el proceso de 1976, sino sustituido por esta. A eso súmese que se perdió la relación directa entre el debate y la reforma, pues el pueblo no discutió normas de un proyecto de ley de reforma constitucional, sino un documento que contenía los aspectos que se analizarían en el IV Congreso del PCC, cuyos resultados se transformaron por la Asamblea Nacional en una ley de reforma constitucional, que terminó modificando a más de la mitad del articulado de la constitución.

Debido a la coyuntura internacional, que definió el inicio de la caída del socialismo en Europa del Este y, sobre todo, a la rápida transición que experimentaron sus constituciones para dar entrada a las instituciones y lógicas liberales, el Partido Comunista Cubano (PCC), mediante acuerdo de su Buró Político, influyó en el proceso de discusión y, lo más trascendente, prefijó a futuro los límites a la reforma de la constitución.

En el acuerdo se planteó la incuestionabilidad del socialismo, la reafirmación del partido comunista y su carácter dirigente, la negación del pluralismo partidista y su consideración como "dogma contrarrevolucionario", el perfeccionamiento de la democracia socialista y revolucionaria, y la proscripción de las instituciones burguesas; en otro sentido, la eliminación de cualquier rezago de desigualdad o discriminación, con especial referencia a las que sufrían los creyentes religiosos. Estos aspectos, si se analizan en relación con la reforma del 2002 -como se verá más adelante-, podría inferirse que ya desde ese momento determinados contenidos propios de la constitución se habían vuelto intangibles.

En julio de 1990, la ANPP aprobó la Ley de Reforma Constitucional. El hecho de no someter a referendo el proyecto de ley de reforma suscitó criterios encontrados, teniendo en cuenta algunas modificaciones que se introdujeron, y que el segundo párrafo del artículo 141 constitucional dotaba de rigidez a la cláusula de reforma, en los siguientes términos: 
Si la reforma es total o se refiere a la integración y facultades de la Asamblea Nacional del Poder Popular o de su Consejo de Estado o a derechos y deberes consagrados en la Constitución, requiere, además, la ratificación por el voto favorable de la mayoría de los ciudadanos con derecho electoral, en referendo convocado al efecto por la propia Asamblea.

Vega Vega ${ }^{56}$ comentaba sobre el requisito del referendo regulado en el segundo párrafo del 141 constitucional, de la siguiente manera:

Se trata de una garantía de las garantías que ofrece nuestra democracia socialista, ya que esta reforma (tanto la sustitución íntegra de la Constitución como la de los aspectos señalados) significaría un paso extraordinariamente importante y trascendental que se refiere o bien al Poder Popular o a los derechos, deberes y garantías para todos que significa nuestra sociedad socialista organizada en un Estado de nuevo tipo. De ahí que cuando se trate de reforma total o parcial relativa a los aspectos señalados, la cláusula que la autoriza adopte la máxima rigidez.

No ha existido un criterio uniforme sobre la envergadura de la reforma del 92. Para Azcuy se trató de un nuevo texto, porque los "núcleos duros" de la constitución de 1976 habían sido cambiados. Este particular término usado por Azcuy tiene el mismo significado que los contenidos bases de una constitución que al ser modificados se está frente a una reforma total de la constitución ${ }^{57}$. En otro sentido, Prieto señala que la reforma permitió conservar los elementos esenciales del diseño socioeconómico y político ${ }^{58}$, y para Guanche la reforma transformó los fundamentos ideológicos del estado cubano ${ }^{59}$.

Las otras causales que conllevaban a la realización de un referendo tenían en cuenta si la modificación se refería "a la integración y facultades de la Asamblea Nacional del Poder Popular o de su Consejo de Estado o a derechos y deberes consagrados en la Constitución". Se sostuvo la tesis de que la ratificación popular en referendo debía entenderse siempre que se limitara, restringiera o eliminase el ejercicio de los derechos (o se ampliasen los deberes). Similar interpretación se

\footnotetext{
56 Vega VeGa (1988), p. 308.

57 Los núcleos duros se relacionaban con la definición y estructuración clasista del estado, el carácter obrero-clasista del partido comunista, la concepción unitaria del poder estatal, la ideología oficial de carácter marxista-leninista, la hegemonía excluyente de la propiedad socialista, a excepción de las otras que reconocía la propia constitución. Para más sobre este análisis, AzCuY EnríQuez (1994), pp. 41-52.

58 Prieto Valdés (2004), p. 45.

59 Guanche Zaldívar (2010), p. 26.
} 
sugirió para los supuestos que significasen disminución de las facultades de los órganos estatales y de la calidad de sus miembros, refiriéndose a la legitimidad directa o indirecta, pues con la reforma de 1992, por primera vez se podrían elegir directamente a los delegados y diputados a las asambleas del poder popular provincial y nacional ${ }^{60}$.

$\mathrm{Al}$ margen de los derechos que se adicionaban con la reforma ${ }^{61}$, con la reforma se perdió la certeza jurídica de todos, al adicionarse el estado de emergencia a la constitución. A causa de ello se prescribía constitucionalmente que una ley (que hasta la fecha no existe) determinaría los derechos y deberes fundamentales reconocidos por la carta magna, cuyo ejercicio sería regulado de forma diferente mientras dure el estado de emergencia (art. 67). Por ende, de alguna manera, se limitaban y restringían los derechos reconocidos constitucionalmente, pues las situaciones excepcionales tienen como una de sus consecuencias la limitación o restricción de estos.

Además, la tesis de Pérez Milián se acoge a una interpretación extensiva de la constitución, solo que técnicamente obvió que este tipo de interpretaciones es válido mientras no signifique limitaciones de derechos, y en este caso se estaba cercenando el derecho de participación, a la vez que se estaba impidiendo que el pueblo expresara en referendo su opinión final sobre la reforma de su constitución.

Al margen de lo anterior, la amplitud de la reforma de 1992, la cláusula de reforma no sufrió cambios. Se mantuvo la previsión de flexibilidad y rigidez constitucional, en dependencia de los contenidos que se someterían a reforma.

\section{2002: LA TERCERA REFORMA}

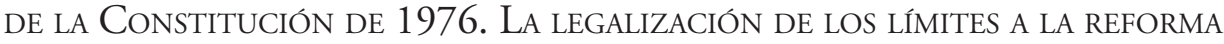

La reforma a la Constitución de 1976, realizada en el 2002, se fundamentó oficialmente en la nueva postura agresiva del gobierno norteamericano. En el escenario interno, en abril de ese año, Oswaldo Payá, uno de los líderes de la disidencia en Cuba (contrarrevolución para el discurso oficial), presentó una iniciativa legislativa a la asamblea nacional, bautizada como el "Proyecto Varela"62, que por su contenido trascendía a la constitución. Las propuestas del Proyecto Varela consistían en derechos a la libre expresión y a la libre asociación, amnistía a los encarcelados por motivos políticos y la libertad a los detenidos por practicar

60 Pérez Milián (1992), pp. 6 y 7.

61 Cfr. artículos 3 (2º párrafo), 41, 55 y 71 Ley de Reforma Constitucional, 13 de agosto de 1992.

62 Para más, cfr. De la Cuesta (2007), pp. 519-531. 
derechos humanos que las leyes actuales no reconocen, derecho de los cubanos a formar empresas tanto de propiedad individual como cooperativas; así como una nueva ley electoral, que modificara la nominación de los candidatos y el propio sistema de elección de los mismos.

Esta iniciativa se amparó en el inciso g) del artículo 88 constitucional, por el cual 10.000 ciudadanos con la condición de electores pueden presentar una iniciativa de ley. Para el "Proyecto Varela" se había reunido un total de 11.200 firmas, pero fue rechazado por la Asamblea Nacional del Poder Popular ${ }^{63}$.

Dos de las cuestiones que pudieron haber sido tenidas en cuenta para desestimar la iniciativa, según lo exigido por el artículo 64 del actual Reglamento de la Asamblea Nacional del Poder Popular, debieron ser lo relativo a la necesidad de que los promoventes acompañen su solicitud por declaración jurada ante notario público, y que se consignasen los resultados de las coordinaciones hechas con los órganos y organismos estatales que estarían involucrados en la materialización de las propuestas (acápite 6). El primero de los requisitos es cuestionable desde el punto de vista práctico y teórico. En Cuba, reunir 10.000 firmas ante notario público implica un esfuerzo notable por parte de la ciudadanía, cuando la práctica internacional es facilitar la recolección a través de fedatarios públicos ad hoc; segundo, porque la participación política debe ser gratuita a fin de facilitar su concreción. En cuanto al segundo requisito, convierte a la iniciativa popular legislativa en una iniciativa controlada por el estado y tendente al fracaso cuando se conciba en contra de los intereses de quienes representan a los poderes constituidos.

Otra cuestión que pudo haberse argüido era que el "Proyecto Varela" estaba concebido como una iniciativa legislativa popular, pero debido a las peticiones que contenía, se configuraba como una iniciativa popular de reforma a la constitución.

La reforma de la Constitución del 2002 tomó como base una propuesta, acordada y firmada, en Asamblea Conjunta de las direcciones nacionales de las organizaciones de masas dirigida a la Asamblea Nacional del Poder Popular. La propuesta tenía como objetivo principal la reafirmación del socialismo, con claras miras en dos aspectos que funcionan como anclajes del sistema político cubano: la dirigencia del PCC como única fuerza política del sistema, así como la preeminencia y control del

63 Oficialmente, también fue repelido este proyecto desde el punto de vista político. En este último sentido, se argumentó que era una estrategia concebida y financiada desde el extranjero y subvencionada por la Oficina de Intereses de los Estados Unidos en La Habana, junto a otros gobiernos hostiles a la Revolución cubana. 
Estado sobre la propiedad y la economía. Una vez más el mecanismo de reforma, previsto esta vez en el artículo 137 de la Constitución de 1976 reformada en 1992, volvía a tensar el mandato de la cláusula de reforma, pues al tenor de esta parecía tener iniciativa de reforma solo la Asamblea Nacional del Poder Popular.

Otra cuestión importante a tener en cuenta en este proceso de reforma es que la Comisión Redactora, ni el resto de los sujetos que intervinieron en la elaboración de la Constitución en 1976, pensaron a futuro que la Constitución cubana podía ser blindada con una cláusula de intangibilidad abierta. El hecho obviamente no es la falta de previsibilidad, que es racional, sino la necesidad de legitimar una decisión político-constitucional de tal envergadura, a través de instrumentos democráticos idóneos para la manifestación de la voluntad del soberano.

Teniendo la Asamblea Nacional la facultad de convocar a referendo, se optó por multitudinarias marchas populares en todo el país (más de 9 millones de cubanos se involucraron), con el fin de demostrar públicamente el repudio popular al injerencismo del gobierno de Estados Unidos y el apoyo a la iniciativa de la Dirección Nacional de las Organizaciones de masas, y por un proceso sin precedentes en Cuba, de recolecta de firmas de adhesión (se lograron 8.198.237), el cual fue catalogado erróneamente como un proceso plebiscitario popular. Así lo consignó la nota de la Asamblea Nacional del Poder Popular publicada en la Gaceta Oficial, y que contenía la Constitución reformada ${ }^{64}$.

Oficialmente se reconoció iniciativa de reforma a las organizaciones de ma$\operatorname{sas}^{65}$. A partir de aquí son posibles dos interpretaciones. La primera es que se actuó al margen de lo prescrito por el artículo 137 constitucional y se consumó una mutación constitucional, lo que sienta como precedente que modificaciones posteriores a la constitución puedan hacerse a instancia no solo de las direcciones nacionales de las organizaciones de masas, sino también del pueblo, sobre la base del propio artículo 88.

La segunda es que, si bien el mecanismo de reforma se estableció en el artículo 137, la Constitución cubana no establece diferenciación entre ley formal y ley en sentido material. Tampoco existe interpretación alguna en este sentido, por

64 Cfr. "Nota de la Asamblea Nacional del Poder Popular", en Constitución de la República de Cuba, 31 de enero de 2003.

65 La Disposición especial de la Constitución (reformada en el 2002) formalizó el sujeto de esta iniciativa, a la vez que reconoció: "El pueblo de Cuba, casi en su totalidad, expresó entre los días 15 y 18 del mes de junio del 2002, su más decidido apoyo al proyecto de reforma constitucional propuesto por las organizaciones de masas en asamblea extraordinaria de todas sus direcciones nacionales que había tenido lugar el día 10 del propio mes de junio [...]”. Constitución de la República de Cuba, 31 de enero de 2003. 
lo que a partir de los incisos d) y g) del artículo 88, que dan iniciativa de ley a las direcciones nacionales de las organizaciones sociales y de masas, y a 10.000 ciudadanos, respectivamente, en relación con el artículo 3 (soberanía popular), cabría la iniciativa popular de ambos para reformar la constitución. Ya desde finales de la década del 70, Álvarez Tabío, en su libro Comentarios a la constitución socialista, había reconocido la existencia de una iniciativa popular de reforma constitucional, en consonancia afirmaba ${ }^{66}$ :

Ni la Constitución ni el Reglamento de la Asamblea Nacional determinan a quiénes corresponde la iniciativa para la reforma o revisión, por lo cual debe aplicarse, a nuestro a juicio, la misma norma constitucional que regula la iniciativa de las leyes $[\ldots]$

No obstante, esta última posición es bastante discutible, a tenor de lo que fundamenta Álvarez Tabío, que encuentra afiliado en Franco Pérez ${ }^{67}$. En ese sentido, la preceptiva de la Constitución cubana se debate entre sus efectos declarativos o abiertos a interpretaciones contextuales y, en congruencia entre su naturaleza formalista o garantista. Cualquier solución debe al menos tributar a un mismo sentido, teniendo en cuenta que se está ante un texto que encuentra escasa defensa judicial.

La reafirmación del socialismo, objetivo de esta nueva modificación constitucional, significó la adición a la carta magna de una cláusula de intangibilidad, de ahí que el artículo 137 quedase redactado de la siguiente manera:

Artículo 137. Esta constitución solo puede ser reformada por la Asamblea Nacional del Poder Popular mediante acuerdo adoptado, en votación nominal, por una mayoría no inferior a las dos terceras partes del número total de sus integrantes, excepto en lo que se refiere al sistema político, social y económico, cuyo carácter irrevocable lo establece el artículo $3^{\circ}$ del Capítulo 1, y la prohibición de negociar bajo agresión, amenaza o coerción de una potencia extranjera como se dispone en el artículo $11^{68}$.

Con la reforma de 2002, al parecer porque no existe interpretación alguna del Consejo de Estado que la corrobore, la práctica constitucional amplió el mecanismo de reforma en cuanto a los sujetos con iniciativa, al integrar los artículos constitucionales 88 y 137. Pero la adición de la cláusula de intangibilidad, junto al segundo párrafo del artículo 3 y al primero del 11, limitó los contenidos

66 Álvarez Tabío (1988), p. 426.

67 Franco Pérez (2004), p. 35.

68 Franco Pérez (2004), p. 35 
constitucionales que pueden ser objeto de reforma, dando al traste cualquier intento de reforma total a la constitución.

La inserción de una cláusula de intangibilidad a la constitución siempre generará debate, a partir del principio lógico-racional que toda constitución es constitución en el tiempo. Se ha sostenido el criterio que la cláusula de intangibilidad tiene más valor político que jurídico en lo que se refiere a su racionalidad y sostenibilidad.

De Vega las asocia a motivaciones históricas y políticas contingentes y circunstanciales, y afirma que pueden denotar debilidades políticas e institucionales. Para ello pone como ejemplo el referendo que decidió la forma republicana en Italia que no ganó por un amplio margen. También afirma que pueden tener la finalidad de "asentar en el más alto nivel normativo, los supuestos ideológicos y valorativos que descansa el régimen político que con la Constitución se pretende establecer"69. En este mismo sentido relaciona un grupo de autores (Ruemelin, Duguit, W. Jellinek, Biscaretti di Ruffia, Pergolesi) que niegan el valor jurídico de la cláusula de intangibilidad ${ }^{70}$.

Mas, las cláusulas de intangibilidad operan para los poderes constituidos ${ }^{71}$, pero no para el poder constituyente originario que no tiene límites ni condicionamientos, salvo los que él mismo pueda imponerse en un momento histórico determinado.

Con la reforma de 2002, el último párrafo del artículo 3 quedó modificado en los siguientes términos ${ }^{72}$ :

El socialismo y el sistema político y social revolucionario establecido en esta Constitución, probado por años de heroica resistencia frente a las agresiones de todo tipo y guerra económica de los gobiernos de la potencia imperialista más poderosa que ha existido y habiendo demostrado su capacidad de transformar el país y crear una sociedad enteramente nueva y justa, es irrevocable, y Cuba no volverá jamás al capitalismo.

Este precepto, en coordinación con el primer párrafo del artículo 137, que impide la reforma total de la constitución, a partir de la irrevocabilidad del sistema político y social, así como del socialismo, induce a cuestionar cuál

69 De VeGA (1999), pp. 247-248.

70 De Vega (1999), p. 262.

71 De Vega (1985), p. 267.

72 Constitución de la República de Cuba, 31 de enero de 2003. 
preceptiva constitucional tributa al contenido de estos términos o expresiones constitucionales, sobre todo por la complejidad teórica, normativa y real de algunos de ellos, en especial del socialismo. También es cuestionable que el artículo 137 exceptúe al sistema económico, junto al político y al social, y se apoye en una remisión normativa al artículo 3, que solo establece taxativamente el sistema político y social.

\section{A MANERA DE CONCLUSIONES}

El nuevo constitucionalismo latinoamericano ha fijado nuevos estándares al proceso democrático de reforma de la constitución. El procedimiento de reforma en Cuba ha sufrido variaciones en su intensidad democrática. Las cláusulas de reforma de las cartas magnas de 1940 y 1976, de alguna manera. Se adelantaron a los contextos constitucionales en los que se encontraban. Sin embargo, hoy la Carta Magna cubana tiene un procedimiento de reforma que impide al titular del poder constituyente manifestarse en toda su potencia y que limita el elemento democrático del referendo a determinados supuestos.

El principio de soberanía popular ha sido una constante constitucional en Cuba que, en los marcos de las reformas a la constitución, si bien ha tenido vías para expresarse, en ocasiones desde el poder se han escogido alternativas que han reducido su esencia, al sacrificarse los mandatos del procedimiento de reforma que apuntaban a su viabilidad.

Sobre la irreductible legalidad del procedimiento de reforma (y no sobre su legitimidad, que es cuestión aparte), so pena de caer en una situación de ruptura constitucional, pueden establecerse valoraciones de diferente grado. $\mathrm{O}$ el procedimiento de reforma se agota en la preceptiva constitucional que específicamente lo consagra, o este puede integrar otra preceptiva constitucional que si bien, explícita y directamente (desde el punto de vista de la sistemática constitucional) no forma parte de él, tributa a su funcionalidad (y en este sentido es válido tener en cuenta la legitimidad).

Desde una postura "sistemático-formal" más que "normativo-positivista", el procedimiento de reforma se reduciría a su regulación en las cláusulas de reforma, salvo que el texto permita la remisión a otra norma extracláusula(s), configurando así una nueva, pero legítima operación constituyente. Razones políticas, como podría ser la correlación de fuerzas que se reproduce en el poder de reforma de la constitución, pueden dar al traste con la continuidad constitucional, en los términos procedimentales preestablecidos, a pesar de su urgencia. Este podría ser el caso chileno, descrito por Zúñiga Urbina en su trabajo Nueva Constitución y 
operación constituyente, el cual no ha sido el único a lo largo de la historia constitucional moderna, o también el propio cubano dentro de unos años, al no poder reformarse la constitución más allá de los límites indefinidos que se establecieron (informalmente) por el Partido Comunista, y por la imposibilidad de que se invoque al poder constituyente.

Pensar en la exactitud de la lógica representativa, es obviar la posibilidad que sucedan enclaustramientos de la constitución por grupos de poder o élites políticas. Para la lógica representativa, la necesidad del cambio constitucional va a conllevar la decisión del cuerpo electoral de trastocar la correlación de fuerzas políticas que encarna el poder revisor de la constitución. Lo que fácticamente no ha quedado demostrado. De ahí que se haga necesario apelar al principio democrático, que encuentra corporeidad normativa en el axioma de la soberanía popular, reconocido en la actualidad, en la gran mayoría de las constituciones vigentes.

Desconocer que el principio de soberanía popular y sus manifestaciones no forman parte implícita del procedimiento de reforma, es negar que el principio democrático informa a toda constitución, y en el caso que nos ocupa, se extiende a sus cláusulas de reforma. La diferencia entre una constitución como la cubana de 1940, que bajo la égida del principio de soberanía popular, reconocía la iniciativa popular de reforma constitucional, la convocatoria a una constituyente para determinados supuestos y el referendo, respecto a otros textos que le sucedieron, y solo previeron la reforma constitucional en los límites de la actuación de un poder revisor de la constitución, o disminuyeron la incidencia del titular del poder constituyente en la reforma, no es que en la primera se heredó una de las instituciones falaces del liberalismo constitucional y en las otras no, sino que la primera estaba informada por el principio democrático y las otras no, o simplemente menos.

La dimensión política de la soberanía se legaliza a través del derecho a la resistencia, cuya previsión en los textos constitucionales junto a las otras formas de manifestación de la participación directa significará llevar hasta sus últimas consecuencias la soberanía jurídica. La soberanía popular y sus manifestaciones son los principales enclaves de la operación constituyente. Desde ella el poder constituyente puede quedar concentrado y activo normativamente para el momento político que se requiera, o simplemente debe ser integrado a partir de sus diferentes enclaves.

El hecho de que algunos textos faculten al pueblo para reclamar la actuación del poder revisor de la constitución, incluso, a instar al poder constituyente mediante la convocatoria a una asamblea constituyente, provoca que se deba trazar la línea divisoria entre continuidad constitucional formal y material. En 
los límites que hoy se sigue entendiendo la continuidad y ruptura constitucional, deja con relativa orfandad teórica el hecho de que algunas constituciones (como lo hizo la Constitución cubana de 1940 en su momento) reconozcan la posibilidad de que el pueblo inste al poder constituyente, sobre la base del principio de soberanía popular. Aún se sostiene la autosuficiencia del poder revisor para asegurar la adaptabilidad de la constitución al cambio y su trascendencia para la continuidad o ruptura constitucional. Postura que se defiende en los siguientes términos:

A partir de aquí la reforma constitucional cobra un sentido distinto: se convierte en un instrumento más para la permanencia y continuidad constitucional, no necesita de la aparición del Poder Constituyente, sino que los Poderes Constituidos tienen capacidad para realizar los cambios necesarios en el Texto Fundamental que aseguren su subsistencia y adecuación a la realidad social. Por ello, la reforma es una garantía extraordinaria del texto constitucional ${ }^{73}$.

En el marco de la Revolución cubana, desde un primer momento se ha desestimado la normatividad del procedimiento de reforma, y con ello su trascendencia para la defensa y superioridad de la constitución. Existen no pocos ejemplos históricos donde se pone en evidencia el "derecho constitucional transitorio". En ellos ha sido relativamente fácil el acoplamiento de los hechos y el derecho constitucionales, en la medida que las constituciones superadas prescribían un procedimiento de reforma ajustado a los estándares representativos, en este particular, significa la actuación de un órgano representativo con mayoría cualificada que actúa como poder de reforma de la constitución y/o a través de un procedimiento (en los límites de los poderes constituidos) diferente al establecido para la ley ordinaria, lo que era resuelto sin grandes traumatismos jurídicos, en la medida que se posicionaba un nuevo grupo político en las estructuras representativas del Estado que se superaba (caso países del extinto socialismo de Europa del Este).

Pero en el caso cubano, el umbral democrático del procedimiento de reforma de la Constitución del 40, para ese momento histórico, presuponía como mínima superación su propia materialización, reto que fue esquivado por el nuevo poder revolucionario y que ha tenido sus consecuencias hasta nuestros días.

En los procesos de elaboración y reforma de la actual Constitución cubana en 1976, la participación ciudadana, como expresión de la soberanía popular,

73 Aranda Álvarez (2012), p. 393. 
en ocasiones se ha instrumentado de manera paraconstitucional. Los mandatos de la carta magna tienen prioridad (no excluyente) sobre cualquier iniciativa que persiga el mismo fin. Ni recolección de firmas, ni discusiones populares, ni marchas multitudinarias deben sustituir las formas de participación previstas en la constitución, a lo sumo solo pueden complementarlas.

Esto no quiere decir, de ningún modo, que sería factible obviar la discusión popular a favor de la hegemonía procedimental del voto, sino que deben complementarse. Una de las limitaciones del voto está relacionada con que impide valorar la intensidad del consenso y del disenso sobre este particular ${ }^{74}$, y en otro sentido, la votación no genera espacios de reconstrucción o regeneración de la opción política. Relacionado con estas limitaciones, están dos de las fortalezas de la discusión popular como mecanismo que pretende la construcción de consensos y dotar de legitimidad a la decisión política, que puede regenerarse democráticamente, a través del debate. La concepción del poder popular en Cuba debe propender a no soslayar o subestimar oportunidades para la participación popular. En colectividades con una alta cultura del debate -cuestión que no predomina en Cuba- la discusión popular se debe estructurar y pautar, estimular dentro de ella la libertad y oposición de ideas, dotar a ese complejo procedimiento de fórmulas que permitan valorar y ponderar los criterios emitidos con efecto modificatorio, y además prever que la información recibida en forma de criterios tenga total transparencia y esté sometida el control popular.

$\mathrm{Si}$, por un lado, los condicionamientos histórico-políticos han llevado a que el PCC sea por mandato constitucional (artículo 5) la única fuerza política que encauza al estado cubano y, por otro, se han desechado los métodos tradicionales para alcanzar la legitimidad: asamblea constituyente (en 1975) y referendo (1992 y 2002), se debe potenciar en todo momento una participación popular que permita calibrar con exactitud y sin limitaciones los niveles de consenso y disenso alrededor del texto constitucional.

Hoy, los intentos de reforma, sobre todo los que se traten de canalizar a través de una iniciativa popular, enfrentan dos límites fundamentales: de un lado, una constitución blindada por una cláusula de intangibilidad, cuyo contenido no se encuentra del todo definido; de otro, una regulación de la iniciativa popular de manera tal que solo puede prosperar mientras no se oponga a los intereses de los representantes de los poderes constituidos, renunciándose así a calibrar en referendo el grado de legitimidad que puedan generar determinadas propuestas políticas.

74 DAHL (1987), pp. 123-146. 
El reto interpretativo que acarrea completar e, incluso, actualizar el contenido normativo del socialismo, como variable constitucional con repercusión para una reforma en Cuba, deberá tener en cuenta la doctrina marxista-leninista, y también las teorías de un marxismo más actualizado, que tengan en cuenta la real correlación de fuerzas y contradicciones de las actuales clases sociales. También debería tratar de buscar, apelando a la discusión popular, ¿qué socialismo quieren los cubanos hoy?, ¿qué principios estarían dispuestos a sacrificar? y ¿cuáles consecuencias sociales asumir?

Irrevocabilidad no significa intangibilidad de las bases políticas, sociales y económicas que sustentan al estado cubano, que obligaría a una ruptura del hilo constitucional y de la continuidad del estado. No obstante, la irrevocabilidad puede tener efectos retardatarios para la adecuación del cambio a las exigencias sociales, sobre todo si de iniciativa popular de reforma se tratase.

La inexistencia en Cuba del control jurisdiccional de la Constitución, que permita a un órgano independiente del resto de los órganos decisorios del estado (especialmente Consejo de Estado, Consejo de Ministros y ANPP), resolver la constitucionalidad de una reforma que exija una interpretación de lo anterior, es esencial para dinamizar el mecanismo y para la defensa de la propia constitución en general. Sería una manera de no someter al verdadero titular del poder constituyente (con una legitimidad per se) a los designios de los poderes constituidos, por muy legítimos que estos puedan resultar. Otra alternativa sería seguir sometiendo la legalidad del mecanismo de reforma a las pretensiones legítimas que desde la participación popular se hagan valer, a través de procedimientos democráticos, a tono con las exigencias del nuevo constitucionalismo latinoamericano, que aseguren una participación real y efectiva de los cubanos para consensuar intereses de orden constitucional.

\section{Bibliografía CITADA}

Álvarez Tabío, Fernando (1988): Comentarios a la Constitución socialista (La Habana, Ciencias Sociales).

Asensi Sabater, José (1996): La Constitución de 1999. Derecho constitucional venezolano (Valencia, Tirant lo Blanch libros).

BREWER-CARÍAs, Allan R. (2004): Constitucionalismo y Derecho constitucional (Caracas, Editorial Jurídica Venezolana).

Azcuy, Hugo (1994): "La reforma de la Constitución Socialista de 1976", en Cuadernos de Nuestra América (Vol. II, No 22), pp. 41-52. 
Aranda Álvarez, Elviro (2012): “La 'sustancialidad' del procedimiento para la reforma constitucional", en Teoría y Realidad Constitucional (No 29 "La reforma constitucional), pp. 389-408.

BIHARI, Ottó (1979): The constitutional models of socialist state organization (Budapest, Akadèmiai Kiadó).

Buch, Luis M. y SuÁreZ, Reynaldo (2004): Gobierno revolucionario cubano. Primeros pasos (La Habana, Ciencias Sociales).

Crisafulli, Vezio (1970): Lezioni di Diritto Costituzionale (Padova, Casa Editrice Dott. Antonio Milano).

Dhal, Robert A. (1987): Un prefacio a la teoría democrática (México, Gernika).

De la Cuesta, Leonel A. (2007): Constituciones cubanas (Miami, Alexandria Library Incorporated).

De Vega, Pedro (1985): La reforma constitucional y la problemática del poder constituyente (Madrid, Tecnos S.A.).

Departamento de Orientación Revolucionario del Comité Central del Partido Comunista de Cuba (1975): Primer Congreso del Partido Comunista de Cuba. Informe Central (La Habana).

Duguit Vega, Pedro (1926): Manual de Derecho Constitucional (Madrid, Francisco Beltrán).

Editora Política (1991): Este es el congreso más democrático. Resoluciones, principales intervenciones y relación de miembros del Buró Político y del Comité Central. 10-14 de octubre de 1991 (La Habana).

García Pelayo, Manuel (1961): Derecho constitucional comparado (Madrid, Manuales de la Revista de Occidente).

GUANCHE, Julio César (2011): “Estado, participación y representación políticas en Cuba: Diseño institucional y práctica política tras la reforma constitucional de 1992" [fecha de consulta: 23 de junio de 2014]. [Disponible en: http://bibliotecavirtual.clacso.org.ar/clacso/becas/20120420112357/guanche201105.pdf].

GUASTINI, Riccardo (2001): Estudios de Teoría Constitucional (México, Universidad Autónoma de México).

JeLLINEK, Georg (1991): Reforma y mutación de la constitución (Traducc. Christian Förster, Madrid, Centro de Estudios Constitucionales).

Lenin, Vladimir I. (1960): Obras escogidas (Tomos 2 y 3). (Moscú: Instituto de Marxismo-Leninismo del CC del PCUS, Ediciones en Lenguas Extranjeras). Nogueira Alcalá, Humberto (2010): "La reforma constitucional en el constitucionalismo latinoamericano", en Boletín Mexicano de Derecho Comparado, nueva serie (Año XLIII, No 129), pp. 1261-1321. 
Pérez Franco, Antonio Filiu (2004): “¿Reformar para petrificar? La reforma de la Constitución cubana de 1976 en junio del 2002", en Anuario "Parlamento y Constitución” (No 8), pp. 215-238.

Pérez Milián, Félix (1992): "Motivos para una reforma”, en Revista Cubana de Derecho (julio-septiembre No 7), pp. 3-7.

Pérez Royo, Javier (1997): Curso de Derecho constitucional (Madrid, Marcial Pons, Ediciones Jurídicas y Sociales S.A.).

Prieto Valdés, Martha (2004): "La reforma a la Constitución cubana de 1976", en Pérez, Lissette y Prieto, Martha (comps.), Temas de Derecho Constitucional cubano (La Habana, Félix Varela), pp. 26-33.

Quiroga Lavié, Humberto (1991): Derecho constitucional latinoamericano (México, Universidad Nacional Autónoma de México, Instituto de Investigaciones Jurídicas).

Sánchez Viamonte, Carlos (1957): El constitucionalismo. Sus problemas (Buenos Aires, Editorial Biográfica Argentina).

Schmitт, Carl (1992): Teoría de la Constitución (Traducc. Francisco de Ayala, Madrid, Alianza Editorial S.A.).

Soto Barrientos, Carl (1992): "La Asamblea Constituyente y la experiencia latinoamericana”, en Estudios Constitucionales (Año 12, o 1), pp. 397-428.

VAnossi, Jorge Reynaldo A. (2002): Estudios de Teoría Constitucional (México, Universidad Nacional Autónoma de México).

Vega Vega, Juan (1988): Derecho Constitucional revolucionario en Cuba (La Habana, Ciencias Sociales).

Vega Vega, Juan (1997): Cuba. Su historia constitucional. Comentarios a la constitución cubana (Madrid, Endymion).

VergotTini, Giuseppe (2009): Derecho constitucional comparado (Traducc. Claudia Herrera, México, UNAM, Instituto de Investigaciones Jurídicas).

Viciano Pastor, Viciano y Martínez Dalmau, Rubén (2001): Derecho constitucional comparado (Valencia, Tirant lo Blanch).

Villabella Armengol, Carlos M. (2009): Historia constitucional y poder politico en Cuba (Camagüey, Ácana).

ZúNíga Urbina, Francisco (2013): "Nueva Constitución y Operación Constituyente. Algunas notas acerca de la Reforma Constitucional y de la Asamblea Constituyente", en Estudios Constitucionales (Año 11, No 1), pp. 511-540. 


\section{NORMAS CITADAS}

Ley No 1, Constitución de la República de 1940, Gaceta Oficial de la República de Cuba No 464, 8 de julio de 1940.

Ley Constitucional para la República de Cuba, Gaceta Oficial de la República de Cuba No 32, 4 de abril de 1952.

Ley Fundamental de 1959, Gaceta Oficial de la República de Cuba No 13, 7 de febrero de 1959.

Constitución de la República y Ley de Tránsito Constitucional, Gaceta Oficial de la República de Cuba No 2, 24 de febrero de 1976.

Constitución, en Gaceta Oficial de la República de Cuba No 7, 1 de agosto de 1992. Constitución de la República de Cuba, Gaceta Oficial de la República de Cuba No 3, 31 de enero de 2003.

Ley de Reforma Constitucional, Gaceta Oficial de la República de Cuba No 12, 21 de junio de 1973.

Ley de Reforma Constitucional, Gaceta Oficial de la República de Cuba No 18, 29 de junio de 1978.

Acuerdo del Buró Político del Comité Central del PCC y del Comité Ejecutivo del Consejo de Ministros, Gaceta Oficial de la República de Cuba No 13, 23 de octubre de 1974.

Ley No 851 de 6 de julio de 1960, Gaceta Oficial de la República de Cuba No 130, 7 de julio de 1960.

Resolución Conjunta No 1 "Nacionalización de empresas de Servicios Públicos y de Centrales Azucareros, propiedad de entidades norteamericanas", Gaceta Oficial de la República de Cuba No 16, 6 de agosto de 1960.

Resolución Conjunta No 2 "Nacionalización de los bancos norteamericanos", Gaceta Oficial de la República de Cuba No 20, 17 de septiembre de 1960.

Resolución Conjunta No 3 "Nacionalización de empresas mercantiles e industriales norteamericanas" en Gaceta Oficial de la República de Cuba No 22, 13 de octubre de 1960.

Proclamas al Pueblo de Cuba, Gaceta Oficial de la República de Cuba (s/No), 6 de enero de 1959.

Constitución de la República Socialista Federativa de Yugoslavia, Secretaría Federal de Informaciones, Beograd, 1963.

Constitución de la República de Ecuador, Consejo Nacional Electoral, Quito, 2008.

Constitución Política del Estado. Asamblea Constituyente-Honorable Congreso Nacional, 2009. 